\title{
El orgullo patrio como estrategia comunicativa en tiempos de crisis
}

\author{
Francisco CABezuelo-Lorenzo \\ Campus de Segovia \\ cabezuelo@hmca.uva.es
}

\begin{abstract}
Resumen:
Este artículo tiene como eje principal la confianza y patriotismo en campañas de comunicación actuales. En estos momentos de crisis, las empresas necesitan recuperar la confianza de sus públicos. En el caso de España, debido a su éxito reciente en competiciones deportivas, el Banco Santander decide apelar a este sentimiento nacional y despertar el débil sentimiento patriótico de los españoles. Tras un profundo marco teórico y revisión del actual contexto de crisis, este artículo se centra en el análisis de una campaña específica del Banco Santander.
\end{abstract}

Palabras clave: Crisis; Publicidad; España; Banco Santander.

\section{Patriotic pride as a communication strategy at a moment of crisis}

\begin{abstract}
:
This article is about confidence and patriotism in contemporary communication campaigns. At this time of crisis, companies need to get back the audience confidence. In the case of Spain, due to the success in sportive competitions, the Santander Bank decides to call for this national feeling and wake up the weak sense of patriotism of Spaniards. After a deep theoretical frame and analysis of the context, this article focuses on the case analysis of a Santander Bank campaign.
\end{abstract}

Key Words: Crisis; Advertising; Spain; Santander Bank

Referencia normalizada:

Cabezuelo-Lorenzo, F. (2014): El orgullo patrio como estrategia comunicativa en tiempo de crisis. Historia y Comunicación Social. Vol. 19. Núm. Especial Marzo. Págs. 455-466.

Sumario: 1.- Introducción y justificación. 2.- Contexto: varias crisis al mismo tiempo. 3.- Hipótesis, metodología y fuentes para el análisis del caso. 4.- Fundamentos teóricos: cuestión de confianza. 5.Análisis del caso. 6.- Resultados y conclusiones. 7.- Bibliografía y fuentes.

\section{Introducción y justificación.}

Nuevas ideas, pensamientos y una nueva creatividad capaz de comunicar con eficacia y sentimiento son necesarias en los mensajes publicitarios. Esta necesidad se hace más que nunca vital en situaciones de crisis como la actual. No hay que 
olvidar que en un escenario donde la desconfianza de los públicos crea escepticismo y rechazo frente a los mensajes publicitarios en el proceso comunicativo, la confianza se convierte en un objetivo intangible de las organizaciones y la comunicación en una estrategia para conseguirlo. La confianza es una actitud, un constructo psicológico, que cuenta con un importante componente afectivo, además del cognitivo y el conativo.

La confianza es hoy el intangible más apreciado por las instituciones, empresas y políticos. En medio de estos tiempos de crisis económica, social y de valores, que nos ha tocado vivir, ciudadanos y empresas se plantean y replantean su consumo, parece surgir una nueva tendencia (Pérez Serrano y Romero Calmache, 2009).

Una gestión eficaz de la comunicación puede generar y mejorar la confianza, porque la comunicación tiene el poder de influir en los individuos, siempre y cuando haya coherencia entre lo que se dice y se hace. La relación entre comunicación y confianza dependerá de la eficiencia de la primera en el diseño de sus estrategias y mensajes (Viñarás Abad, 2013).

Hay que salir de la crisis y recuperar la confianza empezando a creer en nosotros mismos. Este nuevo pensamiento social aparece reflejado en la opinión pública y en la publicidad. Se busca confianza y se necesita seguridad para salir de la crisis. Los ciudadanos, consumidores y usuarios buscamos empresas responsables que cumplan con lo prometido y demuestren su compromiso con el consumidor y con la sociedad (Fernández Sande, 2013).

En este sentido, aparecen anuncios que no venden productos ni servicios directamente, simplemente hablan de valores y principios, de actitudes y de compromiso (Caldevilla Domínguez, 2013). Se trata de anuncios emotivos, que apelan a los sentimientos más que a los beneficios. Es la publicidad corporativa, que nos recuerda -a veces de forma sutil y a veces de forma machacona- los principios y valores de una empresa, institución u organización.

\section{Contexto: varias crisis al mismo tiempo.}

La actual crisis económica, política y social de carácter mundial que vivimos ha hecho que dejemos de confiar en políticos, empresas, instituciones y valores. El sistema mediático y publicitario está bajo el paraguas del megasistema económico y político, y que por tanto los últimos casos de corrupción política y escándalos más actuales como los casos de corrupción ligados a la esfera pública afectan al sistema mediático y publicitario, además de la opinión pública en general (Mut Camacho, 2012). Sirvan como ejemplo el caso Urdangarín, que afecta a la Familia Real, o los escándalos de Gurtel y Bárcenas, en el lado del Partido Popular (PP) o los casos de los ERES supuestamente fraudulentos en la Junta de Andalucía o el caso Amy Martin en la Fundación Ideas, ligada al Partido Socialista Obrero Español (PSOE) o los 
casos de presunta corrupción en Convergència i Unió (CiU) y el entorno de la familia del ex president de la Generalitat de Catalunya, Jordi Pujol, entre otros ejemplos.

Esta desconfianza provoca un miedo e inquietud, que lleva al malestar social y que se traduce en manifestaciones, protestas y altercados, y en una reducción del consumo. Estas situaciones generan a su vez mayor desconfianza, perjudican la imagen del país y contribuyen en un círculo vicioso a fortalecer la desconfianza, el miedo, y cierta parálisis social para avanzar en las soluciones necesarias para volver al crecimiento económico.

En este contexto, la falta de confianza que en estos momentos se vive en España, provocada por la crisis y los numerosos escándalos políticos y empresariales, lleva a los ciudadanos al escepticismo y a una actitud negativa hacia todos los poderes políticos y económicos. Por otro lado, esta situación provoca el deterioro de la imagen de España en el exterior, pero también -y tal vez más grave- la propia imagen que tenemos los españoles de nosotros mismos.

Las crisis generan desconfianza porque dejamos de creer en las posibilidades y capacidad para salir de una situación delicada o incómoda. Así, la confianza adquiere una nueva categoría en esta situación y se convierte en un activo intangible de las empresas y organizaciones, que buscan la manera de generarla, para que calme el malestar social y predisponga de manera positiva hacia soluciones y cambios.

La confianza, que es una actitud del ser humano y es un concepto que se circunscribe por tanto al campo de la Psicología y de la Comunicación, se transmite. Por tanto, la comunicación se revela como una estrategia indispensable para generar confianza a través de mensajes que consigan demostrar la capacidad para salir adelante y la credibilidad de las fuentes emisoras de mensajes. Pero, a veces no es suficiente. La confianza, como actitud, necesita de un componente afectivo. Los consumidores y usuarios, los ciudadanos, en definitiva, necesitan sentir que son comprendidos y apoyados en este duro trance.

$\mathrm{Al}$ mismo tiempo, la confianza es deseada también por aquellos que llevan las riendas de nuestro país y nuestra economía, desde Madrid, Barcelona, Bruselas o Wall Street. Tanto desde el mundo del comercio, los negocios y la política, los profesionales de la comunicación que trabajan al servicio de empresas e instituciones tienen que desarrollar una empatía y sensibilidad para ponerse del lado de los más débiles, especialmente en estos momentos de crisis.

Una forma de generar esta empatía es conectar con tu interlocutor en principios y valores compartidos. En el sector privado se buscan valores que sitúen a la empresa y a sus públicos en el mismo lugar, en un punto de encuentro común. Recuperar la confianza es un objetivo, pero también es un medio, porque la confianza es la base de las relaciones beneficiosas y duraderas en el tiempo. La comunicación es fundamental para recuperar la confianza, y muchas empresas, apuestan por la publicidad corporativa como estrategia (Viñarás Abad \& Cabezuelo Lorenzo, 2012). 
El compromiso de la marca con el país genera un vínculo que busca mejorar nuestra imagen y recuperar la confianza, y a su vez, crear una relación más afectiva con marca. Es la primera vez, en mucho tiempo, tal vez la primera en democracia, que una marca se asocia directamente con los valores nacionales españoles, exceptuando, claro está, el deporte.

Con motivo de campeonatos deportivos de diversa índole y sobre todo en el momento de celebrarse acontecimientos como la Champions League, UEFA, Eurocopa de Fútbol, los Mundiales o los Juegos Olímpicos, numerosas marcas han puesto en marcha en muchas ocasiones campañas especiales de publicidad destinadas a crear nuevos lazos y vínculos sentimentales entre aficionados nacionales de un deporte y su equipo o selección (Sotelo González, 2013). Pero en esta ocasión, el análisis de ese trabajo no se trata de analizar cuestiones de patrocinio y mecenazgo, ya analizadas en otras ocasiones (Cabezuelo Lorenzo y Viñarás Abad, 2009). En este trabajo se analiza el sentimiento español como generador de confianza e identidad entre marca.

Imágenes 1 y 2.- Ejemplos de la alianza Marca España (local) + Marca CocaCola (global) en los años 60 y en la reciente Eurocopa de 2010.
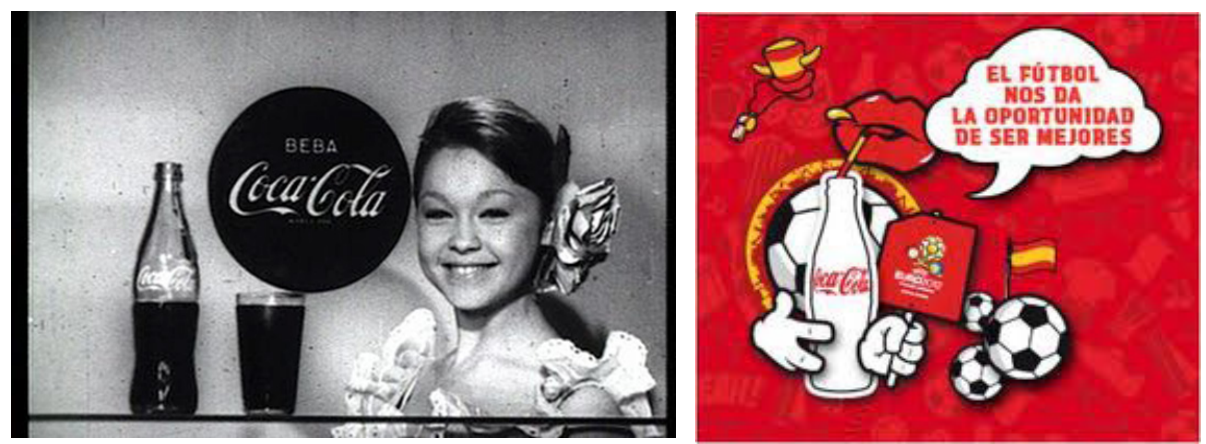

(Imágenes disponibles en Google Pictures).

En esta ocasión, se toma para el análisis una campaña concreta - como es la campaña 'Confianza' del Banco Santander-, aunque también se hace mención a otras, como trabajos previos de otras marcas y compañías, como Coca-Cola, por ejemplo. Este trabajo muestra una tendencia en la comunicación de marca poco común es España. Esta nueva tendencia, fruto de la crisis, de nuestros éxitos deportivos y de las tensiones territoriales o nacionalistas periféricas, consistente en vincular la marca al país a los valores de la empresa. Esta nueva situación surge por primera vez en nuestra historia reciente como resultado de un contexto muy determinado caracterizado por una situación difícil de crisis y falta de confianza. 


\section{Hipótesis, metodología y fuentes para el análisis del caso.}

El presente análisis parte de tres premisas. En primer lugar, la creatividad es indispensable en esta situación de crisis para restablecer la comunicación y generar la confianza necesaria con los públicos, en un contexto actual en el que los mensajes se interpretan con desconfianza y escepticismo por el desolador panorama económico. La segunda tesis de partida considera que la publicidad corporativa basada en los valores es una estrategia eficaz para generar confianza en el público y la confianza es fundamental en la relación con los públicos. En tercer lugar, se puede afirmar que en tiempos de crisis económica y social, es más oportuno y eficaz, realizar publicidad corporativa en valores como la confianza, el esfuerzo, la unión y la esperanza. Sobre estas premisas se desarrolla este trabajo, que pretende, a través del análisis de campañas de publicidad actuales, mostrar esta realidad. Así, el presente escrito profundiza en su primera parte en el estudio de la confianza como actitud desde el ámbito de la Psicología y la Comunicación, para demostrar que las actitudes tienen un componente afectivo indispensable. En la segunda parte, se intentará mostrar a través de un análisis de dos casos cómo las empresas han apostado por una comunicación emocional, basada en comunicar los valores corporativos para generar empatía y afecto hacia las organizaciones anunciadas.

Este trabajo muestra, describe y analiza cómo las empresas recurren a los valores corporativos para generar confianza. De hecho, las palabras "actitud" y "confianza" son cada vez más usadas y recurrentes en eslóganes, 'claims' y en general, los textos publicitarios. Se parte de la hipótesis de que en tiempos de crisis las empresas utilizan los valore corporativos como eje de comunicación en sus campañas de publicidad corporativa. En este caso, la 'proposición de venta' no sería otra que el compartir la necesidad de unión entre los españoles ante la crisis.

Los valores que nos proponen las empresas anunciantes son valores de fraternidad entre ciudadanos identificándonos con ellas al no ligarse a ninguna tendencia política. En otras ocasiones, con motivos de patrocinio, empresas como Movistar, Cruzcampo, Chevrolet, Repsol, Coca-Cola, McDonalds, Adidas o Nike, casi siempre ligados a la selección española de fútbol, han usado el sentimiento español para sus campañas publicitarias, pero siempre ligado a cuestiones deportivas.

De este modo, el beneficio es ético y personal y consiste en tener estos principios en la vida compartidos con la marca y actuar de acuerdo a ellos. El objetivo de estas campañas es influir en el componente cognoscitivo (aportando nueva información sobre aspectos positivos de la sociedad española) y en el componente afectivo (provocando emociones y sentimientos positivos que buscan la unión y buenas relaciones entre la ciudadanía española), para modificar las actitudes, acabar con el pesimismo y salir de la crisis. 


\section{Fundamentos teóricos: cuestión de confianza}

La actitud es una predisposición aprendida que impulsa al individuo a comportarse de una manera consistentemente favorable o desfavorable en relación con un objeto determinado. Las creencias se basan en conocimientos previamente adquiridos, comunicados y compartidos. En el caso del sentimiento de españolidad: hablamos de la identidad, una cuestión personal, cuestionada y cuestionable, sobre todo en la actual España de las sensibilidades autonómicas, regionales y sobre todo nacionalistas periféricas.

Este componente afectivo implica trabajar con emociones, sentimientos y valoraciones, llevando la Comunicación y la Publicidad al terreno de lo emocional, pero también hay que buscar en la Psicología los últimos avances en inteligencia emocional. El componente afectivo ve en actitud una emoción, un afecto o sentimiento que una persona siente por un referente, hacia una marca o producto.

¿Se puede sentir afecto por una empresa, organización o institución? ¿Hacia un banco o hacia una marca de embutidos? Incluso, podemos hacernos otra pregunta: ¿Debe o puede una institución establecer relaciones "afectivas" con sus públicos? ¿Cómo se pueden establecer esas relaciones? Las emociones, como parte de la inteligencia y su influencia en la toma de decisiones, han visto un gran avance en su investigación en los últimos veinte años.

Las acciones que apuntan en esta dirección se convierten en el concepto estratégico del mensaje publicitario, el comportamiento de la organización da lugar a una campaña de publicidad, concretamente, la proclamación de sus valores corporativos, como eje de la campaña. Estamos en una nueva fase del posicionamiento, un posicionamiento corporativo, basado en atributos de la corporación y no del producto.

En conclusión, la confianza es una actitud, y por lo tanto, tiene esta triple naturaleza. Los afectos del individuo son el objeto de este trabajo, pues es el estudio de las afecciones de la persona hacia las marcas lo que ocupa el eje principal de este trabajo, tal y como ser verá a continuación a través del análisis de los valores corporativos en la estrategia creativa de la campaña publicitaria del Banco Santander.

\section{Análisis del caso.}

Para mostrar y analizar la presencia de los valores que apelan al sentimiento de los españoles como pueblo que necesita unirse para salir de la crisis en la estrategia creativa se han tomado como referencia la campaña de publicidad del Banco Santander. Esta empresa ha llevado a cabo una serie de campañas publicitarias basadas en mensajes de sentimiento patrio, en transmitir al público cuáles son los principios de actuación que rigen su conducta y su compromiso social con todos los españoles en estos momentos de crisis. Es decir, cómo es la organización, su identidad corporativa ligada a la sociedad a los sentimientos de los ciudadanos españoles. 
Esta expresión del cómo soy conlleva un componente subjetivo alejado de las características racionales y objetivas de precios, números, etc. Lo que convierte el mensaje publicitario en una manifestación de principios que busca enlazar con los principios del público, con sus sentimientos y su identidad nacional. Compartir valores, hace que se genere empatía y conexión entre empresa y público que coinciden en la base de su identidad. Además, este tipo de publicidad utiliza un lenguaje emocional a través de adjetivos y sintagmas. Apela al sentimiento de unidad huyendo de viejos complejos.

En la primavera de 2007 se celebró en el Círculo de Bellas de Artes de Madrid una exposición sobre la publicidad y la propaganda del primer franquismo (1939-1959) cuya comisaria era la historiadora Susana Sueiro Seoane. En esta exposición sobre nuestro país en la postguerra, en la que la única visión de España permitida era la de los vencedores de la contienda bélica que fracturó el país, se analizan los valores fascistas y franquistas y su reflejo en la publicidad del momento.

La exposición revisaba varios casos de anuncios publicados en medios impresos (periódicos y revistas de la época) en los que los valores de la victoria nacional franquista quedaban patentes. Las marcas directamente respondían a esos valores conservadores, tradicionales y nacional-católicos propuestos por el régimen totalitario que invadía estos aspectos de las relaciones comerciales, del consumo privado y hasta de la vida privada.

Imágenes 3, 4, 5 y 6.- Ejemplos de anuncios publicados en prensa entre 1939 y 1959 en los que se ligan productos y servicios a la ideología franquista y fascista en la España de postguerra.
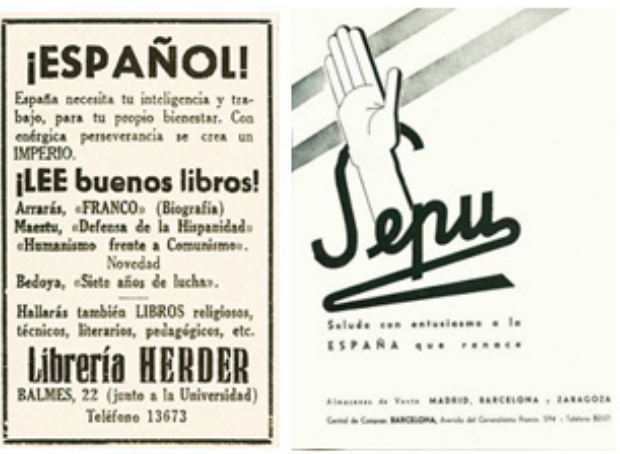
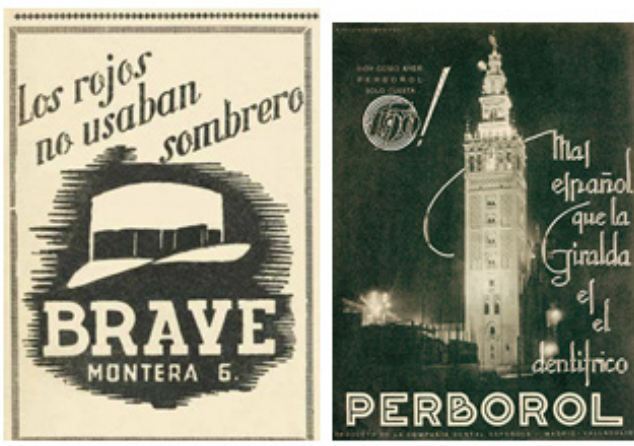

(Imágenes tomadas de/disponibles en Google Pictures).

Este trabajo intenta reflejar una tendencia en la publicidad emocional basada en valores que buscan generar confianza entre el público receptor de los mensajes. La creatividad en la estrategia y el mensaje se revela fundamental, en un ámbito de las organizaciones, donde la coincidencia de valores es muy alta, y por lo tanto, la diferenciación también. Estos valores tienen una influencia trascendental en las acti- 
tudes, comportamientos, y toma de decisiones, sobre todo a la hora de optar entre las posibles maneras de actuar, huyendo en el caso de los anuncios analizados de claros posicionamientos ideológicos derecha/izquierda o centralista/nacionalista.

Algunos autores estiman que los valores sociales son concepciones de lo deseable que influyen en el comportamiento selectivo, entendiendo como aquello deseable lo que es digno de ser deseado (García López, 2012: 28). Por tanto, se constituyen en criterio para la acción entre las diversas opciones disponibles. Además, para otros autores la confianza únicamente puede nacer por referencia a unos valores superiores al interés inmediato de emisor y receptor. "El concepto de bien común no está lejos del concepto actual de responsabilidad social", afirma Jordi Xifra Triadú (2003: 51).

Desde el 18 de noviembre de 2012, el Banco Santander, una de las grandes marcas internacionales españolas, líder en el sector bancario tanto nacional como iberoamericano y con fuerte presencia en todo el mundo, puso en marcha esta campaña centrada en su público español.

Imagen 7.- Fotograma del anuncio 'Confianza' del Banco Santander

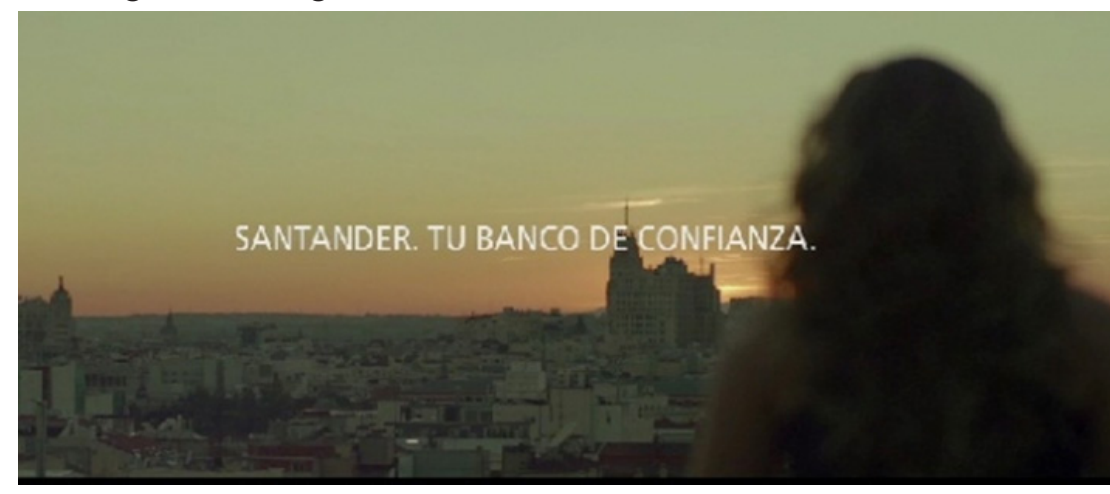

(Google Pictures)

Se trata de una campaña puesta en marcha por la agencia TBWA. En este spot televisivo disponible también en Internet, se retrata a los diferentes actores de la sociedad, jóvenes, emprendedores, triunfadores en el deporte, mayores, familias, empresarios con imágenes de archivo de otros anuncios previos del Banco Santander.

Todos los actores participantes, entre los que se incluyen desde imágenes de camareros, empresarios, estudiantes becados por Universia-Santander o el mismo piloto Fernando Alonso (escudería Ferrari con patrocinio también del Grupo Santander), cuentan con un papel importante en este proyecto que pide la unión e implicación de todos los participantes para lograr el fin de la crisis. Se trata sobre todo un mensaje de esperanza.

El anuncio dura tan sólo 57 segundos. Ha estado presente en todas las televisiones y en Internet, contado a fecha 01 de febrero de 2013 con más de 16285 visitas. El texto íntegro del anuncio es el siguiente. 
¿Sabes lo que hace que un país funcione? La confianza. Confiamos en quien nos quiere y en quien nos cuida y en los que pelean todos los días en una lucha sin medallas, en quienes no nos decepcionan. Sabemos que podemos contar con su talento, con su entusiasmo. Confiamos en nuestra capacidad de unirnos en los malos momentos porque ya lo hemos hecho antes. Confiamos en quienes hacen todos los días todo lo posible y quienes han decidido no rendirse y nunca, nunca, nunca vamos a dejar de confiar en el futuro, porque el futuro tiene nombre y apellidos. Nuestro país está lleno de personas, ideas y proyectos en los que se puede confiar. Santander, tu banco de confianza.

Según el blog 'El Programa de la Publicidad', “en un clima de pesimismo generalizado, el Banco Santander se atreve a ir más allá de la oferta de productos habitual en su amplia cartera", para dar un paso más y "recuperar la confianza de los ciudadanos". Es un mensaje de optimismo que pretende "conseguir remontar la situación de crisis y desánimo" instalada en la sociedad española. Finalmente, con el cierre "Banco Santander. Tu banco de confianza" se busca dar un giro a la situación de negatividad que se vive día a día, lanzando un mensaje de fuerza, de unión, para alcanzar un objetivo común.

En el texto lingüístico se cita en un total de más de siete veces el sustantivo "confianza" y la forma verbal "confiamos". La repetición es por tanto el elemento más básico y más usado. Lingüísticamente nunca se dice a palabra "España" de manera explícita. Se ven banderas de España y el color rojo, pero no se hace alusión directa al concepto de nación. Se habla sólo de país. Sí se hace sin embargo mención y alusión a la idea de nación, en un momento de altas tensiones territoriales, sobre todo por el proyecto soberanista/independentista del actual gobierno catalán presidido por Artur Mas. "Confiamos en nuestra capacidad de unirnos en los malos momentos porque ya lo hemos hecho antes", se afirma de manera pragmática para salir de la crisis sin caer en citas históricas o ejemplos. Simplemente, se apela a la experiencia.

La aparición de la bandera y los colores nacionales aparecen ligados al fútbol y a las competiciones deportivas en las que España ha triunfado, pintado en la cara de aficionados asistentes a un partido o animando a Fernando Alonso.

Las personas unidas para enfrentar el futuro unidos una vez que son conscientes de sus logros comunes son el eje común a las dos campañas. Según estas campañas, el futuro es una posibilidad para labrar un presente inmediato conjunto. El futuro no existe por sí mismo. Existe si se trabaja por un bien común y por el futuro conjuntamente, codo con codo. En estos anuncios e vende esperanza. Se vente tiempo. En este futuro que nos prometen están grandes empresas en las que no hay crisis. Hay certezas. Hay seguridad. En el futuro no hay crisis, sino que todo está por escribir. ¿Por qué? Porque "el futuro pertenece a quienes creen en la belleza de sus sueños", tal y como afirmaba Eleanor Roosevelt. Si hay algo aspiracional -lo que todos deseamos que sea mejor- es el futuro. Como el futuro está por llegar, tiene todo lo bueno y todas las posibilidades. Por eso, el futuro es tan motivador y encaja en el lenguaje publicitario. El futuro es parte del lenguaje y la estrategia creativa 


\section{Resultados y conclusiones.}

A modo de conclusión general, se puede afirmar que este trabajo demuestra que la confianza es una actitud, y como tal, es un activo intangible de las organizaciones que disminuye en situaciones de crisis. La comunicación es una estrategia eficaz para generar confianza. La transmisión de los valores corporativos de las organizaciones genera empatía con el público, lo que refuerza el componente afectivo de la confianza.

Estos mensajes basados en valores corporativos generan esperanza. Son motivadores y eficaces porque sitúan a la organización y el público en un mismo objetivo, en un espacio conjunto y común, en el que se comparten principios y valores. La publicidad corporativa basada en los valores es una forma creativa de llegar al público, generar empatía y sirve para aumentar la confianza. Esta tendencia nos dice que los valores corporativos se convierten en protagonistas indiscutibles en la estrategia creativa para alcanzar un objetivo afectivo en los públicos. Así, se puede afirmar de modo más general que los valores compartidos generan confianza porque crean empatía al compartir principios comunes. El afecto en forma de valores compartidos es el eje creativo de la estrategia.

En situaciones de crisis la publicidad corporativa apuesta por las emociones más que por la racionalidad centrada en el producto, o la marca, y sus cualidades frente a la competencia. Apelar a mensajes como el liderazgo de las empresas, la excelencia, la calidad, incluso el precio, podría contrastar con la situación económica de los consumidores. Parece que en estas situaciones, es más efectivo mostrar los valores que permiten mirar hacia delante y pensar en un futuro mejor.

Tras el análisis, hay que enumerar algunas conclusiones concretas. En primer lugar, hay que recordar que las empresas no hablan de ellas, hablan de las personas que la forman y, sobre todo, de los consumidores y del público en general que comparten los valores de la compañía. Esos consumidores y esos públicos son los que hacen posible el avance, el futuro. Las personas son las protagonistas, el núcleo de la estrategia creativa. No lo es el liderazgo, ni el éxito, ni las acciones ni la calidad de los productos. Como segunda conclusión, hay que decir que la entidad financiera del Banco Santander, presidida por Emilio Botín, ha creado un mensaje de "confianza" contextualizado en un momento álgido de la actual situación de crisis que vivimos. Junto al deterioro de la marca España y la falta de confianza en la capacidad del país por parte de inversores internacionales y nacionales, esta iniciativa del Santander busca el toque humano que refuerce la imagen del banco y sus proyectos dentro de España. Hace un llamamiento a las personas y su valía para salir adelante. Este mensaje sorprende por su mensaje directo, apelando claramente a confiar, y haciendo alusión a las posibilidades reales que tenemos - como personas y como país- porque ya se ha demostrado de qué somos capaces en un pasado, en la historia más lejana, reciente y actual.

Finalmente, es preciso recordar que el anuncio del Banco Santander usa el recuerdo de hechos demostrados para reforzar esta idea. Es una comunicación valiente y 
arriesgada. Es un mensaje muy directo que incluso se atreve a utilizar una imagen de la bandera española, algo muy poco usual en nuestra publicidad, por las tensiones nacionalistas y los problemas de identidad nacional. La repetición de la palabra "confianza" en el caso del banco redunda en un mensaje apelativo y directo que busca la empatía con los públicos y anima a salir adelante y superar el actual momento de crisis.

Se observa una tendencia en la publicidad actual a incluir en la estrategia creativa los valores corporativos para generar confianza a través del elemento afectivo de las actitudes. Este estudio pretende mostrar cómo las empresas buscan crear vínculos afectivos con sus públicos, para generar confianza, un activo que gana valor con la crisis.

Los valores generan confianza porque nos identificamos con ellos y, compartirlos es ver en el otro lo mismo que en nosotros, creando empatía. La retórica en el lenguaje contribuye a la belleza y la eficacia del mensaje, la repetición y los paralelismos reiteran el mensaje, los valores, y crean un mensaje esperanzador acompañado de una música motivadora, emotiva y con imágenes donde las personas son las protagonistas. Se buscan escenas o experiencias en las que el público se vea reflejado y se sienta reconocido.

\section{Bibliografía}

CALDEVILLA DOMÍNGUEZ, D. (2013). Efectos actuales de la sobreinformación y la infoxicación a través de las bitácoras y del proyecto I+D Avanza 'Radiofriends'. Revista de la SEECI. Núm. 30. Págs. 34-56.

FERNÁNDEZ SANDE, M. (2013). La crisis de la prensa en España: análisis del caso Público, un diario nacido a contracorriente. Revista de Comunicación 'Vivat Academia'. No 122 . Págs. 22-39.

HAWKINS, D., BEST, R., \& CONEY, K. (2004): Comportamiento del consumidor. México, Editorial McGrawHill.

HOGG, M. \& VAUGAHN, G. (2010): Psicología social. Madrid, Ed. Médica-Panamericana.

GARCÍA LÓPEZ, J. (2012). Sujetos, cosas y publicidad. Entre el éxito social y la discriminación. Revista de Comunicación 'Vivat Academia'. Número especial. Págs. 28-30.

MUT CAMACHO, Magdalena (2012). Apuntes de la opinión pública a pie de calle. Revista de la SEECI. Núm. 28. Págs. 1-10.

PÉREZ SERRANO, M ${ }^{\mathrm{a}}$ J. \& ROMERO CALMACHE, Mª (2009): La gestión de las personas en el nuevo entorno empresarial de la comunicación. Revista de Comunicación 'Vivat Academia'. No 109. Diciembre-enero. 2009-2010. Págs. 1-23.

SCHIFFMAN, L. \& KANUK, L. (2005): Comportamiento del consumidor. Madrid, Pearson Education. 
SOTELO GONZÁLEZ, J. (2012). Deporte y social media: el caso de la Primera División del fútbol español, en Historia y Comunicación Social, № 17. Págs. 217-230.

VIÑARÁS ABAD, M. \& CABEZUELO LORENZO, F. (2009): "El patrocinio como técnica comunicativa en grandes eventos: el caso de Expo Zaragoza 2008", en 'Actas del I Congreso Internacional Brand Trends'. Coord. María Isabel de Salas Nestares, Valencia, 2009.

VIÑARÁS ABAD, M. \& CABEZUELO, F. (2012): "Publicidad corporativa y de la RSC, ¿oportunidad o alternativa en tiempos de crisis para ganar confianza?". Comunicación presentada en el III Congreso Internacional de la Asociación Española de Investigadores en Comunicación (AEIC) en Tarragona, enero de 2012.

VIÑARÁS ABAD, M. (2013). Estrategias de comunicación para generar confianza, en Revista Comunicación y Hombre, N 9, Madrid, Editorial Universidad Francisco de Vitoria.

XIFRA TRIADÚ, J. (2003): Teoría y Estructura de las RRPP. Madrid, McGrawHill.

\section{Notas}

Este trabajo no habría sido posible sin la colaboración de la profesora Dra. Da ${ }^{\text {a }}$ Mónica Viñarás Abad, de la Facultad de Humanidades y Ciencias de la Comunicación de la Universidad San Pablo CEU de Madrid.

\section{El autor}

Francisco Cabezuelo Lorenzo es Doctor Europeo en Tecnologías, Estructuras y Tratamientos de la Información (UCM). Cuenta con un Máster Oficial Universitario en Marketing y Comunicación Corporativa (USJ). Ha sido becario de postgrado de la Fundación "la Caixa" en Public Relations Management (McGill, Canadá) y de la Fundación Caja Madrid en The Queen's University of Belfast (Irlanda del Norte). Es Licenciado en Periodismo (UCM) y Licenciado en Publicidad y RRPP (UCJC). En la actualidad es profesor en la Facultad de Ciencias Sociales, Jurídicas y de la Comunicación del Campus de Segovia de la Universidad de Valladolid (España). Gracias a los programas académicos de cooperación Erasmus ha sido profesor visitante en universidades de Bélgica, Italia, Países Bajos y Reino Unido. 